\title{
Measurement of section thickness in quantitative microscopy with special reference to enzyme histochemistry
}

\author{
A. D. PEARSE AND R. MARKS1 \\ From the Institute of Dermatology, London, and The Welsh National School of Medicine, Cardiff
}

SYNOPSIS Quantitative histochemical techniques demand constancy in sectioning tissue and preferably knowledge of the true thickness of a section. In this investigation a simple, rapid, accurate, and reproducible technique is described for measuring section thickness using an instrument known as a Surfometer. It has been shown that: (a) cryostat microtome settings bear little relationship to the true section thickness of the sections produced; (b) that different instruments differ in their inaccuracies; (c) that this inaccuracy varies slightly with different tissues.

If densitometric methods are used and either the absolute amount of a tissue component is to be measured or the amount of a tissue component is to be compared in two tissues then it is mandatory to determine the actual thickness of the section. The method described here seems the most appropriate one for these investigations.

Microscopy of all types is rapidly progressing from an era of detection and description to a time when the importance of quantitation is appreciated. This is especially true of enzyme histochemistry.

The introduction of microdensitometry has produced a new concept in quantitative microscopy (Deely, 1955). The Vickers scanning and integrating microdensitometer which has been used in this investigation measures the light transmitted by a tissue section at a chosen wavelength and depends on the Beer-Lambert law (Atkin, 1970). Its use to measure any tissue component in absolute terms or to compare the content of the component in different tissues (or in the same tissues in different circumstances) demands a rigidly standardized system of tissue preparation. Amongst the variables that occur during section preparation are: (1) Accessibility and retention of the tissue component under consideration which depends on the methods of fixation (or quenching) and storage chosen. (2) Demonstration of the tissue component under consideration. This depends on the particular histochemical test used. (3) The amount of tissue being assayed. This depends on section cutting.

'Please send requests for reprints to Dr R. Marks, Department of Medicine, University Hospital of Wales, Heath Park, Cardiff CF4 4XN

Received for publication 25 April 1972.
The first two of these classes of variables are easily standardized in any histochemistry laboratory. The third type of variable listed above has been much more difficult to check and is potentially a very large source of error in quantitative histochemistry. In this investigation we have attempted to demonstrate the importance of knowing true section thickness by using an instrument designed to measure the exact step height and surface contours of metal and ceramic surfaces.

\section{Materials and Methods}

The instrument used in this investigation was the Surfometer (Planer Products Ltd, Sunbury-onThames, Middlesex; Type SF100; see fig 1). This instrument is designed to provide a contour display and centre line 'average roughness' of surfaces. It has been used predominantly up till now to examine metal and ceramic surfaces in the light engineering and electronics industries. The instrument uses a displacement transducer to monitor the movement of a diamond stylus which is made to traverse the surface to be evaluated. A flat plate is used as a reference datum so that true contour is shown. The displacements of the stylus are indicated on the instrument's meter and are recorded on a moving chart. The sensitivity of the machine can be arranged 


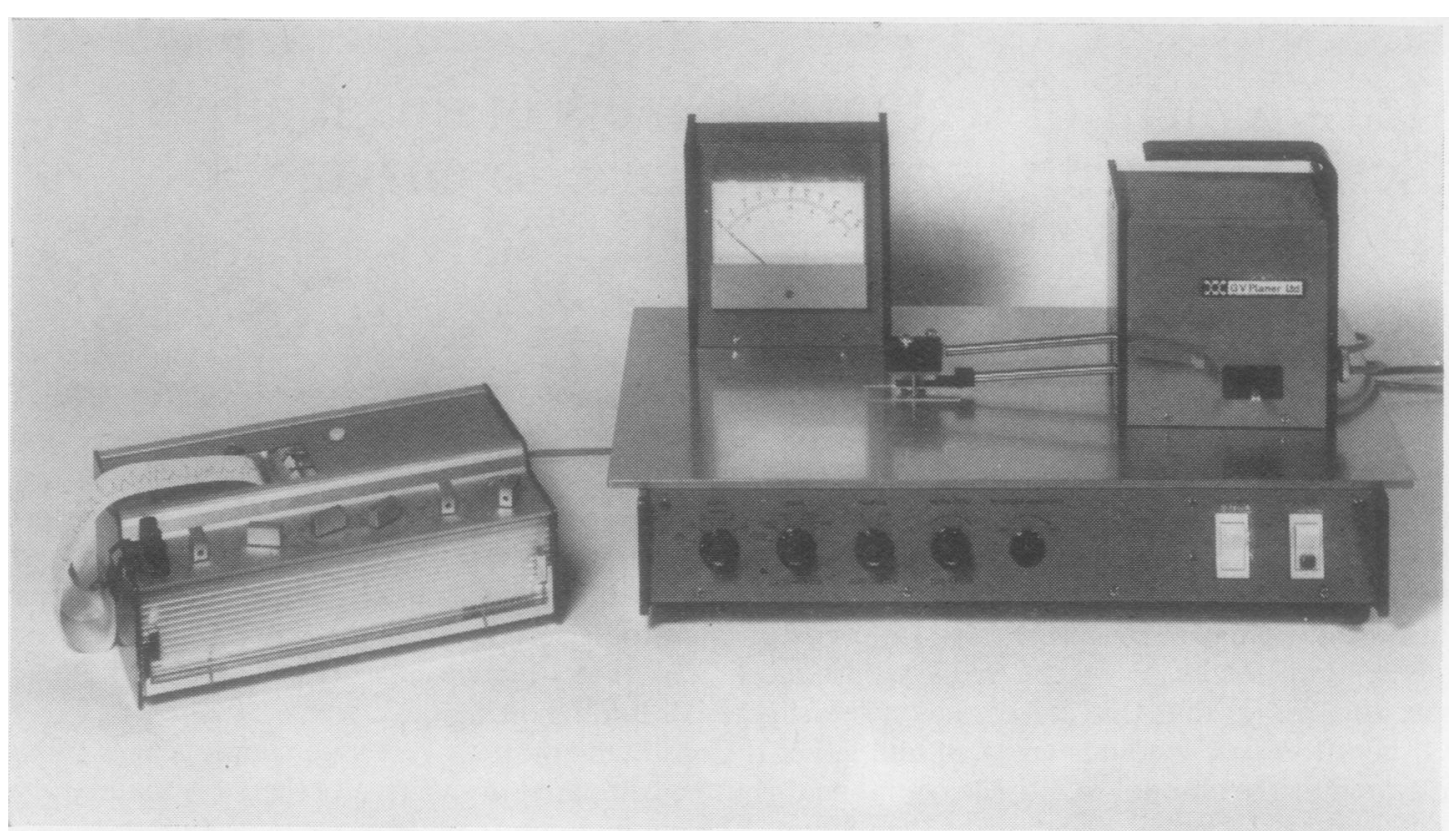

Fig 1 The Surfometer type SF100

so that full scale deflections are recorded for features of $3,10,20,50$, or 100 microns profile.

To assess the accuracy of the Surfometer two feeler gauges stated to be 25.4 and 50.8 microns in thickness were measured. Feeler gauges are used in the electronic and engineering industries to measure, by touch, the gap between two parallel faces. The observed widths of these gauges were $25 \cdot 1$ and $49 \cdot 5$ microns respectively.

\section{TISSUES}

Tissues used in this investigation were obtained from hairless mice ( $\mathrm{hr} / \mathrm{hr}$ ) and from a $3 \mathrm{~mm}$ 'punch' biopsy from the forearm of a normal human volunteer subject who had given his informed consent. The tissues were chilled immediately in hexane free from aromatic hydrocarbons and cooled to $-70^{\circ} \mathrm{C}$ by immersion into a bath containing a mixture of cardice and alcohol.

\section{SECTION CUTTING}

Sections were cut at various microtome settings on a Bright's cryostat containing a Cambridge rocking microtome. They were air dried and their thickness was measured on the Surfometer after the specified times.

The effect of drying time on section thickness was measured using sections of mouse liver cut at a microtome setting of 10 microns and dried for periods of from five minutes to six hours. Six consecutive sections were cut and measured at each time interval.

The actual thickness of sections from a variety of tissues was measured and compared. Six sections of each of mouse liver, kidney, and spleen, and human skin were sectioned at microtome settings of 2 to 24 microns and their thicknesses measured on the Surfometer at least five minutes after sectioning.

\section{Comparison of cryostats}

Two Bright cryostats in regular use of similar design and condition containing identical microtomes were compared. The actual thickness of sections of mouse liver cut at microtome settings of 2 to 12 microns was measured on the Surfometer at least five minutes after sectioning.

\section{CORRELATION OF SECTION THICKNESS WITH} MICRODENSITOMETER ESTIMATION OF

ENZYME HISTOCHEMICAL REACTION PRODUCT Mouse liver sections were cut at microtome settings of 4 to 14 microns and their actual thickness was measured on the Surfometer between five and 15 minutes after sectioning. The sections were than incubated in a reaction mixture for $\mathbf{1 5}$ minutes to demonstrate succinic dehydrogenase activity (Chayen, Bitensky, Butcher, and Poulter, 1969). Two sections were cut and reacted at each microtome setting. The density 


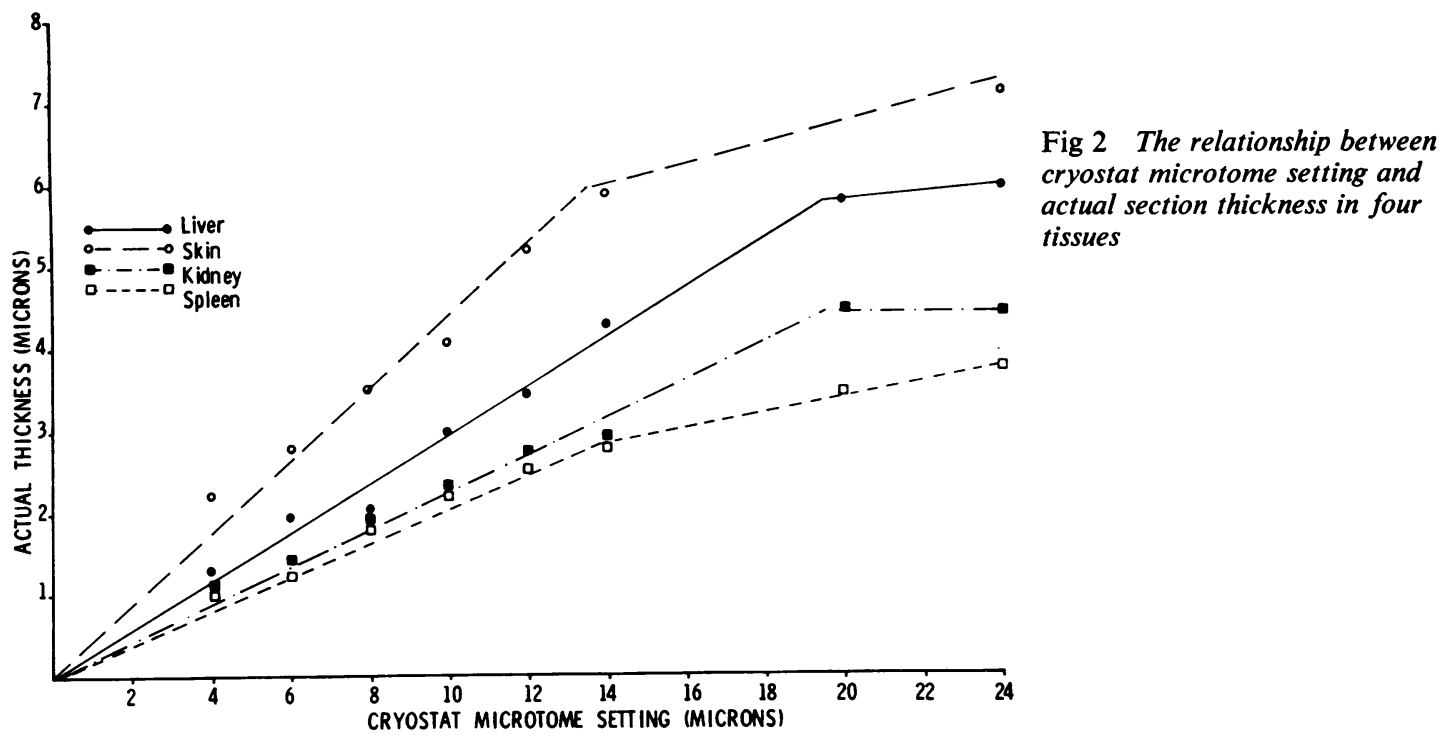

of the resulting reaction products was measured in a Vickers M-85 scanning and integrating microdensitometer.

\section{Results}

The effect of section drying on actual section thickness showed that from five minutes to six hours the true section thickness remained identical.

In fig 2 the actual section thicknesses have been plotted against the microtome setting at which they were produced. The table shows thestandard errors of the means for these observations. It can be seen that there is a wide divergence between the observed true section thickness and the microtome settings. All four tissues examined showed similar, but not identical, differences between actual thickness and the microtome settings.

The difference in the actual section thickness between sections cut on two cryostats but at the same settings are shown in figure 3.

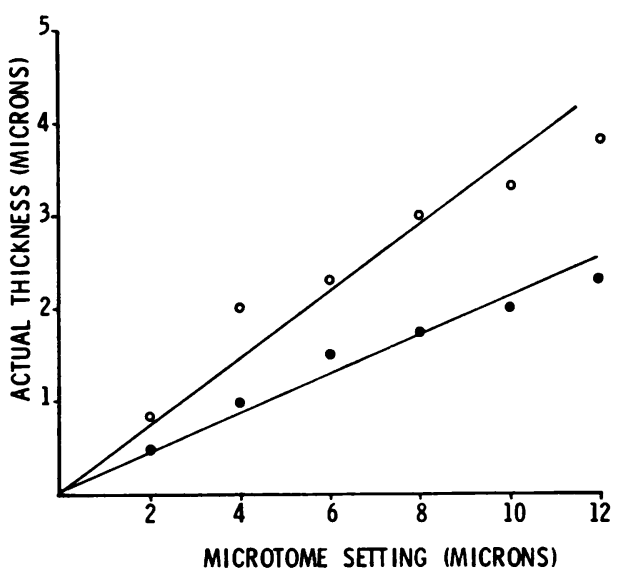

Fig 3 A comparison of two cryostats in cutting liver sections

\begin{tabular}{|c|c|c|c|c|}
\hline Thickness in Microns & $\begin{array}{l}\text { Liver } \\
\text { SEM }\end{array}$ & $\begin{array}{l}\text { Kidney } \\
\text { SEM }\end{array}$ & $\begin{array}{l}\text { Spleen } \\
\text { SEM }\end{array}$ & $\begin{array}{l}\text { Skin } \\
\text { SEM }\end{array}$ \\
\hline $\begin{array}{r}4 \\
6 \\
8 \\
10 \\
12 \\
14 \\
20 \\
24\end{array}$ & $\begin{array}{l}0.04 \\
0.04 \\
0.04 \\
0.04 \\
0.07 \\
0.04 \\
0.16 \\
0.07\end{array}$ & $\begin{array}{l}0.04 \\
0.00 \\
0.04 \\
0.04 \\
0.06 \\
0.04 \\
0.12 \\
0.10\end{array}$ & $\begin{array}{l}0.04 \\
0.08 \\
0.04 \\
0.00 \\
0.04 \\
0.00 \\
0.04 \\
0.07\end{array}$ & $\begin{array}{l}0.07 \\
0.07 \\
0.12 \\
0.12 \\
0.09 \\
0.11 \\
0.11 \\
0.12\end{array}$ \\
\hline
\end{tabular}

Table Standard errors of the mean for the four tissues relating to figure 2 


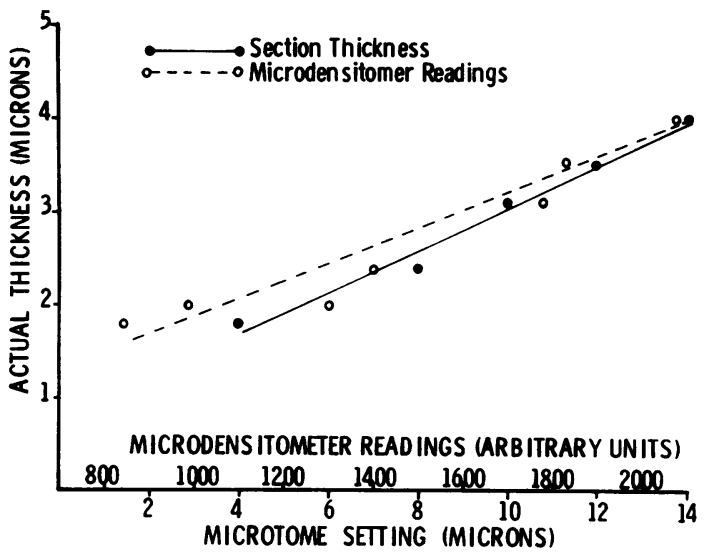

Fig 4 The comparison of actual thickness with microtome setting and microdensitometric succinic dehydrogenase estimation in liver tissue.

The relationship between actual section thickness, microtome setting, and densitometric readings resulting from the succinic dehydrogenase reaction is shown in figure 4.

\section{Discussion}

It seems from the results presented in this paper that all the tissue sections measured were much thinner than the stated microtome settings by a factor of 3 or 4. We suggest that some of this discrepancy was due to loss of moisture at the time of sectioning. From the standard errors given in table $I$ it can be seen that this method of measuring section thickness has a high degree of reproducibility. The stylus does not appear to injure the tissue in any way. It should be noted that each tissue type varied in actual thickness at any particular microtome setting although they followed a similar pattern.

In any quantitative technique that relies on densitometric observations the thickness of the sections being examined must be constant and preferably known. We have shown in this investigation that the cryomicrotomy techniques in use at present are inadequate. Felgenhauer and Glenner (1966) extracted aminopeptidase from unfixed kidney sections cut at microtome settings ranging from 8 to 32 microns. They found that enzyme activity increased more than the increase in section thickness. They tried to find the optimum 'section thickness' at which to estimate enzyme activity by densitometric measurement of the histochemical reaction product. These workers concluded that 10-micron sections were best although they could not have known the true thickness of their sections. Butcher (1971) developed a chemical method for determining section thickness in which nucleic acid is extracted from the section. Severe limitations of this method are the resulting destruction of the tissue and the complexity of the procedure. Butcher found that by varying the cutting speed of the microtome the calculated section thickness varied between 9.6 and $20 \cdot 1$ microns for the same microtome setting. An automatic constant speed device fitted to the cryostat will make cryomicrotomy a more reliable and reproducible procedure but still does not allow conclusions to be drawn as to the actual thickness of sections produced.

There has been a long history of attempts to measure the thickness of microtome sections (Lange and Engström, 1954), but none have been completely successful. We believe that the method described here in which rapid and accurate measurements can be taken before an enzyme histochemical reaction is the most appropriate way to determine true section thickness.

Dr R. Marks is in receipt of grants from the MRC and the Wellcome Trust.

The authors wish to thank G.V. Planer for their help and the use of a Surfometer for this work.

\section{References}

Atkin, N. B. (1970). Principles and applications of the Deeley integrating microdensitometer. Introduction to quantatitive cytochemistry 2, edited by G. L. Wied and G. F. Bahr p. 1. Academic Press, New York and London

Butcher, R. G. (1971). The chemical determination of section thickness. Histochemie, 28, 131-136.

Chayen, J., Bitensky, L., Butcher, R. G., and Poulter, L. (1969). A Guide to Practical Histochemistry. Oliver and Boyd, Edinburgh.

Deeley, E. M. (1955). An integrating microdensitometer for biological cells. J. sci. Instr., 32, 263-267.

Felgenhauer, K., and Glenner, G. G. (1966). Quantitation of tissue bound renal aminopeptidase by a microdensitometric technique. J. Histochem. Cytochem., 14, 53-63.

Lange, P. W., and Engström, A. (1954). Determination of thickness of microscopic objects. Lab. Invest., 3, 116-131. 